\title{
Coopercuc: percursos de valorização dos recursos locais e de convivência com o Semiárido
}

\author{
Coopercuc: valorization paths of local resources \\ forliving in harmony with the semiarid climate
}

Coopercuc: caminos para la valorización de los recursos locales y para la convivencia con la región semiárida

Chiara Gentile Andrés Burgos ${ }^{b}$

${ }^{a}$ Doutora em Desenvolvimento Sustentável pelo Centro de Desenvolvimento Sustentável da Universidade de Brasília-CDS/UnB, Brasília, DF, Brasil End. Eletrônico: chiara.pcin@yahoo.it

${ }^{\mathrm{b}}$ Doutorando do Centro de Desenvolvimento Sustentável da Universidade de Brasília - CDS/UnB, Brasília, DF, Brasil End. Eletrônico: anburgosdelgado@unb.br

doi:10.18472/SustDeb.v7nEsp.2016.18321

\section{RESUMO}

Dentro do contexto de apropriação discursiva da convivência com o semiárido brasileiro, a história e a evolução da experiência da Cooperativa Agropecuária Familiar de Canudos, Uauá e Curaçá (Coopercuc), BA, exemplificam a afirmação exitosa de eventos e processos sociais e culturais aptos para reverter os efeitos de alguns dos fatores históricos e sociopolíticos associados às principais fragilidades dessa região. Diante disso, este estudo tem o objetivo de examinar o sentido de convivência com o semiárido a partir da análise dessa experiência de agricultura familiar e prática de desenvolvimento rural no semiárido. Para atingir o objetivo, foi realizada uma pesquisa exploratória por meio de visitas de campo, entrevistas semiestruturadas e coleta de dados qualitativos, visando à reconstrução da história da cooperativa e à avaliação de seus efeitos. As conclusões apontam para processos, agentes e resultados que constroem uma experiência situada de desenvolvimento que, por gerar caminhos possíveis de mudança e benefícios duradouros integrados com o tecido social local, pode ser considerada virtuosa.

Palavras-chave: Semiárido brasileiro. Coopercuc. Desenvolvimento local. Capital social. Agricultura familiar. Convivência com o semiárido. 


\begin{abstract}
The history and evolution of the experience of the Cooperativa Agropecuária Familiar de Canudos, Uauá and Curaçá - Coopercuc, located in the state of Bahia, (Northeastern Brazil), exemplify the successful assertion of events and socio-cultural processes that can reverse the effects of some of the historical and sociopolitical factors associated with the main weaknesses of the Brazilian semiarid region. This article presents the context of this region and its critical issues. It seeks to show the sense of coexistence with the semiarid climate resulting from participation in the cooperative and in agroecological practices. It examines in an exploratory mode the history of Coopercuc, through field work, semi-structured interviews and qualitative data collection. Findings point to processes, agents and results that build a local development experience, which can be considered virtuous because of the sustainable and local social relations that foster integrated pathways of change and benefits.
\end{abstract}

Keywords: Brazilian semiarid region. Coopercuc. Local development. Social capital. Family farming. Living in harmony with the semiarid.

\title{
RESUMEN
}

Dentro del contexto de apropiación discursiva de la convivencia con la región semiárida brasileña, la historia y la evolución de la experiencia de la Cooperativa Agropecuaria Familiar de Canudos, Uauá y Curaçá (Coopercuc), Bahía, ejemplifican la afirmación exitosa de los acontecimientos y procesos sociales y culturales capaces de revertir los efectos de algunos de los factores históricos y sociopolíticos asociados a las principales fragilidades de la región. Considerando esto, este estudio tiene como objetivo examinar el significado de la convivencia con la región semiárida a partir del análisis de esta experiencia de agricultura familiar y de la práctica del desarrollo rural en la región semiárida. Para lograr este objetivo, se realizó una investigación exploratoria a través de visitas de campo, entrevistas semiestructuradas y recolección de datos cualitativos, orientados a la reconstrucción de la historia de la cooperativa y a la evaluación de sus efectos. Las conclusiones apuntan a procesos, agentes y resultados que construyen una experiencia situada de desarrollo que, por generar posibles vías de cambios y beneficios duraderos integrados con el tejido social local, puede ser considerada virtuosa.

Palabras clave: Semiárido brasileño. Coopercuc. Desarrollo local. Capital social. Agricultura familiar. Convivencia con la región semiárida.

\section{INTRODUÇÃO}

Ao longo da história, o semiárido brasileiro tem sido tratado como uma questão a ser resolvida, já que essa região, caracterizada por grandes períodos de estiagem, é fortemente marcada pela fome crônica e a pobreza. Todas as mazelas do semiárido são tradicionalmente atribuídas às características físicas da região, especialmente ao clima, que se impõe como o grande vilão do desenvolvimento e do drama nordestino.

Esse enfoque dado à seca legitimou um discurso e um modelo de desenvolvimento fundamentados na vitimização do semiárido. Tal discurso serve para que se atribua à natureza problemas políticos, sociais e culturais, historicamente construídos, e gerou ações emergenciais de combate à seca. Em muitos casos, políticas de desenvolvimento concebidas e executadas atualmente na região têm ainda esse viés imediatista e paternalista e tentam artificializar a natureza com o objetivo de acabar com a semiaridez para salvar a região e transformá-la em um lugar de prosperidade (BAPTISTA; CAMPOS, 2013a).

Diante desse cenário, a visão da assim chamada "convivência com o semiárido" representa um modelo alternativo de superação das desigualdades e de promoção da emancipação da população em relação às necessidades básicas, para lidar com a seca e os impactos negativos associados. Nesse contexto, algumas ações em prol do desenvolvimento territorial, de valorização da agricultura familiar e dos recursos locais têm mostrado a superação dos empecilhos historicamente associados ao semiárido brasileiro. Levando em conta o princípio da convivência com o semiárido e algumas reflexões da 
ciência social sobre capital social, processos de criação e valorização dos recursos locais e da cultura do desenvolvimento, consideramos essas experiências como sendo exemplos de sucesso e conjuntos de boas práticas. Esse é o caso da Cooperativa Agropecuária Familiar de Canudos, Uauá e Curaçá (Coopercuc), BA, escolhida como estudo de caso para este trabalho.

Desse modo, este artigo teve como objetivo analisar a experiência da Coopercuc, mediante a reconstrução de sua história de vida, para ilustrar os fatores diferenciadores que a tornariam um modelo de gestão socioambiental capaz de dar respostas às fragilidades associadas ao semiárido.

A primeira seção do artigo apresenta uma breve contextualização do semiárido brasileiro. Na sequência, e de maneira sucinta, se expõem os principais elementos que marcam a transição do combate à seca em direção à convivência com o semiárido. Em seguida, são indicados e sinteticamente descritos alguns fatores históricos e sociopolíticos associados às principais fragilidades do semiárido, os quais servirão de base para justificar as razões pelas quais o estudo de caso é considerado virtuoso, dentro do contexto de apropriação discursiva da convivência com o semiárido. A seção sucessiva é empírica, incluindo os procedimentos metodológicos e a apresentação do estudo de caso, mediante o relato da história e a evolução da experiência da Coopercuc. Por fim, são apresentados os resultados e a discussão, assim como as considerações finais do estudo exploratório.

\section{O SEMIÁRIDO BRASILEIRO}

O semiárido brasileiro é a maior região semiárida do mundo em extensão territorial e densidade demográfica (MIRANDA; TIBÚRCIO, 2013). A região semiárida corresponde a 18,2\% do território nacional. Essa área compreende aproximadamente $80 \%$ do Nordeste brasileiro e abrange 1.133 municípios de nove estados (MIN, 2005), como mostra a Figura 1. Sua população estimada é de 23 milhões de habitantes, dos quais cerca de 8 milhões estão localizados na zona rural, o que faz desta a região que concentra a maior população rural do Brasil (INSA, 2014).

A delimitação do semiárido brasileiro é baseada em pelo menos um dos seguintes três critérios: precipitação média anual inferior a 800 milímetros, índice de aridez de até 0,5 e risco de seca maior que $60 \%$ (INSA, 2012). A região apresenta um regime pluviométrico de grande variabilidade espacial e temporal, com longos períodos secos e chuvas concentradas em poucos meses do ano. Esse padrão de chuvas irregular associado a altas disponibilidades de energia solar e temperaturas elevadas provocam um grande déficit hídrico, uma vez que a precipitação é três vezes menor que a quantidade de água que evapora da superfície (MARENGO, 2008). Apesar de ser o semiárido mais chuvoso do mundo, mais de $90 \%$ de suas águas não são aproveitadas devido a sua evaporação e escoamento superficial, mas também ao limitado sistema de armazenamento (MALVEZZI, 2007).

O semiárido tem a maior parte do seu território coberto pela Caatinga. Contrastando com sua variedade de tipos fisionômicos de paisagens e relevância biológica, a Caatinga, único bioma restrito ao território brasileiro, concentra mais de $60 \%$ das áreas susceptíveis à desertificação e pode ser considerado um dos mais ameaçados do Brasil e de maior vulnerabilidade diante das mudanças climáticas globais (LEAL et al., 2003). Essa vulnerabilidade a variações climáticas tem como fator mais crítico para a Caatinga a disponibilidade de água, já que apesar de ser adaptada à seca, a vegetação do semiárido apresenta alta sensibilidade na resposta a crises hídricas prolongadas (SEDDON et al., 2016). Diante do atual cenário de mudanças climáticas, a sensibilidade da Caatinga pode ter um impacto sobre a resiliência do bioma, a prestação e manutenção dos serviços ecossistêmicos e o bem-estar humano.

Essas características da região dificultam, mas não impedem a convivência com o ambiente. Em geral, e embora a participação da indústria e dos serviços na economia do semiárido tenha aumentado nos últimos 50 anos, a pecuária e o plantio de culturas de subsistência ainda são a base da sociedade rural e a principal atividade econômica dos municípios da região (MIN, 2005). Segundo o último censo agropecuário, o semiárido contabilizou 1,7 milhão de estabelecimentos agropecuários, sendo $89 \%$ de agricultura familiar (IBGE, 2006). Esses pequenos estabelecimentos familiares (minifúndios) contribuíram com $31 \%$ do valor total da produção agrícola do semiárido (IBGE, 2006). Contudo, a grande parcela de estabelecimentos agropecuários de pequena propriedade familiar tem pouca 
capacidade para servir de base para o sustento das famílias e viabilizar, nas condições do semiárido, sustentabilidade em um sentido amplo (BUAINAIN; MIRANDA; GARCIA, 2013; TIBÚRCIO, 2013). As transferências de renda baseadas principalmente no emprego público, aposentadorias e o Programa Bolsa Família têm também peso importante na economia (ARAÚJO; LIMA, 2009). Contudo, essa é ainda a região com os piores indicadores sociais do Brasil e concentra mais da metade (58\%) da população pobre do país (INSA, 2014).

Outro fator significativo para a compreensão da realidade do semiárido é a identidade cultural, caracterizada por uma rica e diversificada gama de representações e experiências que têm definido a construção da história do povo sertanejo na Caatinga.

\section{A CONVIVÊNCIA COM O SEMIÁRIDO COMO ESTRATÉGIA E DESAFIO DIANTE DA SECA}

A concepção da seca como problema tem orientado a atuação de muitos governos sob a lógica do combate à seca. Por muito tempo o modelo de desenvolvimento sociopolítico e econômico de combate à seca contribuiu para fortalecer a imagem que estigmatiza o semiárido, dando-lhe uma configuração negativa que foi propagada e consolidada no imaginário social.

A convivência com o semiárido nasce como contraponto às abordagens desenvolvimentistas historicamente aplicadas ao semiárido desde o Brasil Império (século XIX) até o fim dos governos militares (1985). A viabilidade da transformação da realidade semiárida está atrelada a uma nova cultura de superação das desigualdades, da pobreza e da miséria e a um caráter propositivo para lidar com a seca e as mazelas associadas.

A passagem de uma concepção de combate à seca para um enfoque de convivência com o semiárido abandona a tendência antropogênica de combate à natureza para se situar no lugar da convivência mediante uma visão sistêmica do ambiente que inclui dimensões geofísicas, sociais, econômicas, políticas, culturais e todas as suas inter-relações. Entre as orientações necessárias para construir esse "sentido de convivência", alguns autores (SILVA, 2006; CONTI; PONTEL, 2013) destacam: universalização e democratização do acesso à terra e à água; promoção de uma educação contextualizada; incentivo às atividades e práticas produtivas apropriadas; promoção de políticas de segurança alimentar e nutricional; desenvolvimento de pesquisa e disseminação de conhecimentos e tecnologias apropriadas ao semiárido; acesso aos serviços básicos; e preservação e uso sustentável dos recursos naturais.

Essa transição vem sendo construída, durante as últimas três décadas, a partir de um amplo processo de mobilização que se iniciou envolvendo movimentos e organizações ligados à Igreja Católica, a partidos políticos e ao terceiro setor, graças a grupos de pessoas empenhadas no trabalho social com os setores mais pobres da população. Durante esse tempo, diversas ações de diferentes organizações, desde movimentos sociais e políticos atuantes, até academia, organizações do terceiro setor e governos locais, vêm contribuindo para a convivência solidária e sustentável com o semiárido mediante a construção, a promoção e reaplicação de diferentes conhecimentos e práticas inovadoras (FONTANA et al., 2015).

\section{FATORES DESAGREGADORES NO CONTEXTO DO SEMIÁRIDO BRASILEIRO}

A questão da seca sempre foi colocada no centro dos debates sobre o semiárido brasileiro e apresentada como elemento gerador da maioria dos problemas da região (BURSZTYN, 1984; BAPTISTA; CAMPOS, 2013d). Contudo, isso não significa que os longos períodos de estiagem sejam a causa fundamental dos problemas regionais. A seguir, apresentam-se alguns condicionantes advindos de processos sociais e políticos vivenciados historicamente que, de maneira interconectada, estão na raiz das desigualdades estruturais que marcam a sociedade do semiárido e reforçam seu sentido de hostilidade. 


\section{SUBDESENVOLVIMENTO}

A natureza no sertão é trabalhada discursivamente como a causa principal do atraso regional responsável pela miséria que atinge a região (CASTRO, 2003). A reprodução e difusão no imaginário regional de um discurso que apresenta a Caatinga como natureza hostil e coloca o semiárido como "região problema" criaram o mito de que a pobreza decorria da terra, das condições físicas e climáticas desfavoráveis, e da "raça" da sua gente (SILVA; RODRIGUES; SILVA, 2014). Essa ligação imediata entre a seca e a pobreza foi o pretexto de muitas das formas de intervenção governamental de longa tradição no semiárido, dentro de uma orientação emergencial para combater a seca, que beneficiavam prioritariamente a pecuária, em detrimento do interesse da maior parte da população rural (SILVA, 2006).

Porém, o que está na origem do atraso econômico e social no semiárido são fatores estruturais internos e externos que, interconectados, contribuem para a manutenção das fragilidades sociais, explodindo como calamidade em cada período de estiagem prolongada. Entre esses fatores, Castro (2003) destaca o regime inadequado de propriedade e a estrutura fundiária da região, a exploração dos trabalhadores e a orientação da terra para uma agricultura de exportação, em detrimento da produção interna de alimentos para a subsistência.

\section{ASSISTENCIALISMO E POLÍTICAS EMERGENCIAIS}

O enfoque dado à seca por diferentes grupos sociais, baseado na vitimização do semiárido, gerou a chamada "indústria da seca" (BAPTISTA; CAMPOS, 2013a). A indústria da seca pode ser entendida como um processo político que instrumentalizou a seca e privilegiou grandes obras descontextualizadas para o atendimento dos interesses das oligarquias locais, enquanto mantinha a pobreza de populações subordinadas (NEVES, 2006). A lógica da indústria da seca se materializava na realização de obras fantasmas ou faraônicas, como a construção de grandes açudes, barragens e poços perfurados em terras de fazendeiros (BAPTISTA; CAMPOS, 2013a). Ao mesmo tempo, a concepção de combate à seca estava por trás da execução de políticas emergenciais que atendiam aos interesses econômicos das elites dominantes, como a distribuição de alimentos, as frentes de serviço, o deslocamento populacional e, mais recentemente, a distribuição de água em carros-pipa (NEVES, 2001; ALVES, 2013).

As políticas de natureza assistencialista e coronelista nas quais se sustenta o combate à seca contribuíram para que as estruturas consolidadas de poder locais, e todas as relações sociais adjacentes, acabassem permanecendo quase que intocadas até a década de 1980 (BURSZTYN, 1984). Em muitos casos, ainda hoje, as políticas de desenvolvimento que estão sendo executadas no semiárido não consideram as peculiaridades da região e ampliam processos de concentração de poder e dependência econômica e política, favorecendo a criação de um "novo coronelismo" modernizado (BAPTISTA; CAMPOS, 2013a).

\section{ESTRUTURA E PROPRIEDADE FUNDIÁRIA}

Apesar de a agricultura familiar ser importante para a geração e distribuição de renda e recursos no semiárido, a maioria de minifúndios tem pouca capacidade para garantir o sustento dos agricultores e suas famílias (MIRANDA; TIBÚRCIO, 2013). A agricultura familiar está restrita a pequenos espaços de terra disponibilizados pelos produtores de grandes áreas. A concentração de terra (e água) nas mãos de uma pequena elite, detentora do poder político e econômico, é histórica e gera altos níveis de exclusão social e de degradação ambiental, consolidando uma cultura política baseada na submissão, no clientelismo e no paternalismo (BURSZTYN; CHACON, 2011). Essa desigualdade na distribuição da terra compromete ademais a segurança alimentar e nutricional dos agricultores familiares. Entre os fatores que contribuem para a desigualdade no acesso à terra estão a especulação imobiliária e a produção do agronegócio para exportação. 


\section{DESEMPREGO E ÊXODO RURAL}

As severas condições climáticas do semiárido, somadas às dificuldades de acesso à terra, à água, ao crédito e a uma política agrícola adequada para a região, condenam as pessoas à pobreza, à dependência política e ao abandono da terra (BAPTISTA; CAMPOS; QUINTELA, 2014).

A histórica estrutura concentradora de riquezas e, mais recentemente, os grandes projetos de mineração, energéticos e de irrigação que se instalam na região agravam esse quadro de expulsão da população e de desagregração de muitas famílias. Embora as políticas de transferências de renda ajudem a segurar parte da população no meio rural, a migração do semiárido para as principais capitais brasileiras e cidades do Nordeste continua sendo muito grande e a região caminha para atingir o índice de urbanização brasileiro, 85\% (ALVES; SOUZA, 2015).

\section{EDUCAÇÃO DESCONTEXTUALIZADA}

Historicamente, as escolas e o ensino oferecidos ao povo do semiárido preparavam para o êxodo e estimulavam os alunos e alunas a migrarem para outras regiões, com o argumento de que o semiárido era inviável para quem queria progredir na vida (PEREIRA, 2013). Atualmente, na maioria dos casos, a educação no semiárido continua distante da identidade e realidade local, pois não leva em consideração o contexto no qual a escola está situada, com suas peculiaridades, limites e potencialidades (SANTOS et al., 2011).

O mesmo direcionamento descontextualizado da educação formal foi implementado na extensão agrícola, com a formação de profissionais sob uma perspectiva basicamente produtivista. Esse modo de pensar a assistência técnica tem gerado outro tipo de desertificação, relacionada com a "poda" de ideias e iniciativas dos agricultores, considerados desprovidos de conhecimento (BAPTISTA; CAMPOS, 2013b, p. 102).

\section{ORGANIZAÇÃO E MOBILIZAÇÃO SOCIAL}

Diante da constatação dos principais problemas do semiárido, nos últimos anos, a trajetória dos movimentos sociais organizados passou a oferecer uma multiplicidade crescente de abordagens e alternativas produtivas para incrementar os recursos hídricos, adaptados à realidade local, e que visam melhorar as condições de vida das populações (CORDEIRO, 2013).

Porém, deficiências de caráter organizacional e de capacitação técnico-operacional, aliadas a insuficiências materiais e financeiras, diminuem a capacidade de intervenção e de controle social das organizações da sociedade civil nos programas implantados em âmbito local. Entre os principais entraves destacam a baixa qualificação dos recursos humanos locais, a pouca capacidade de articulação política e a fragilidade dos mecanismos de participação popular e de controle social (BAPTISTA; CAMPOS, 2013c).

Além dos aspectos que dificultam a organização e atuação dos movimentos sociais no semiárido, deve-se notar a necessidade de superar as barreiras enfrentadas pelo cooperativismo no âmbito da agricultura para viabilizar a produção e inserção dos pequenos produtores nos mercados locais e globais e melhorar o desenvolvimento da economia rural.

\section{INSEGURANÇA ALIMENTAR E DESNUTRIÇÃO}

A questão da segurança alimentar e nutricional no semiárido não pode ser dissociada do processo estrutural de desigualdade que deforma, historicamente, o desenvolvimento econômico e social dessa região. A vulnerabilidade alimentar ocasionada pela renda familiar reflete a associação entre fome e pobreza e se manifesta no estado nutricional das famílias e, mais especificamente, das crianças.

Além disso, a prática incentivada pela política do agronegócio tem conseguido convencer algumas famílias de agricultores familiares a mudarem sua forma de produção, trocando a diversidade de cultivos pela monocultura (ROCHA, 2013). Esse caminho leva as famílias a um círculo vicioso de 
dependência de insumos externos, de perda da sociobiodiversidade associada à agricultura familiar e de degradação dos recursos naturais. Nessas condições, o cenário apresentado não ajuda a melhorar o perfil alimentar das famílias do semiárido, por si mesmo qualitativa e quantitativamente deficiente, mas, sim, a aumentar ainda mais a distância entre a situação real e as recomendações básicas de uma alimentação saudável (VALENTE, 1997; BRASIL, 2006; BURITY et al., 2010).

\section{RELAÇÕES DE GÊNERO E GERAÇÃO}

As mulheres são as que mais sofrem no contexto do semiárido, pois são colocadas diante de uma dupla marginalização: "a marginalização econômica e social, por viverem no semiárido, e a marginalização por serem mulheres" (BAPTISTA; CAMPOS, 2013a, p. 59). A desigualdade de gênero no semiárido se reflete especialmente nos seguintes espaços: sistemas de produção; acesso ao crédito; tarefas domésticas e cuidado das crianças; processos de formação profissional e escolarização; gestão da propriedade e espaços políticos de decisão (SANTOS, 2014).

Outra questão importante quando se fala de construir um semiárido com maior inclusão social, participação e cidadania é a discussão sobre geração, especialmente com foco voltado para a juventude (SCHISTEK, 2013). A migração geralmente tem sido uma alternativa frustrada para a sobrevivência de jovens que saem das suas comunidades pelo desejo de ter uma vida melhor. $\mathrm{O}$ desafio aqui está em encontrar novos caminhos para inserir esses jovens nos espaços de debate e atuação, para que possam conhecer melhor sua realidade e se sintam pertencentes aos processos de transformação do semiárido.

\section{FONTES E MÉTODOS}

O presente trabalho é fruto de dois momentos de pesquisa: (1) levantamento e consulta de fontes bibliográficas; (2) pesquisa de campo.

A pesquisa bibliográfica se deu por meio de consulta em periódicos de cunho científico, livros e ensaios da literatura especializada, e visou levantar informações relativas ao contexto geográfico e socioeconômico do estudo de caso. Para a pesquisa documental foram utilizados também relatórios, planos, publicações e materiais informativos produzidos pela Coopercuc.

A pesquisa de campo foi realizada em janeiro de 2014 no município de Uauá (BA), especialmente na comunidade de Lajes das Aroeiras, durante cinco dias de permanência e de visitas aos grupos de produtores, nos diferentes locais de produção e nas unidades de beneficiamento.

O município de Uauá foi escolhido como campo da pesquisa empírica (i) por representar o local de nascimento e de difusão da experiência estudada; (ii) por ser o município de residência dos atoreschaves que protagonizaram a história da cooperativa e que hoje ocupam cargos técnicos e de gestão; (iii) por ser o local onde a cooperativa, seus órgãos e sua fábrica central estão sediados.

Durante as visitas de campo foram realizadas entrevistas semiestruturadas e abertas com diversos atores, tais como produtores, lideranças locais, habitantes da região e funcionários da Coopercuc. Foram entrevistados os fundadores da cooperativa, seus membros mais antigos, os presidentes (passados e o atual), o técnico de produção, a responsável pela comunicação, a responsável do setor de venda e agricultores (homens e mulheres, pertencentes a diferentes faixas etárias). As entrevistas e as visitas foram realizadas com base em roteiros visando: (i) à reconstrução histórica; (ii) ao levantamento de dados qualitativos e quantitativos relativos ao desempenho da cooperativa; e (iii) à identificação de todas as tipologias de resultados (monetários e não monetários, individuais/familiares/comunitários, temporários e duradouros) que a cooperativa pode ter proporcionado e que os agricultores familiares percebem e relatam.

Outros instrumentos de coleta de dados utilizados foram: histórias de vida, coleta de material de áudio e fotográfico e observação direta. A exploração e a reconstrução do contexto, das histórias, do papel dos agentes e dos atores envolvidos servem de base para esta análise qualitativa, e são captados e restituídos por meio de "descrições densas" (GEERTZ, 1973). 
A perspectiva dos relatos de campo é diacrônica, em função da reconstrução da história e evolução dos vários projetos de desenvolvimento local que se subseguiram ao longo de mais de três décadas. Além disso, a avaliação da experiência estudada envolve aspectos sociais, econômicos e ambientais, levando em consideração indicadores qualitativos de base, entre eles:

- continuidade e nível de autonomia dos projetos;

- salvaguarda dos recursos ambientais;

- geração de renda e de benefícios sociais não monetários;

- repartição dos benefícios/renda gerados;

- estímulo à formação de organizações sociais em âmbito profissional e/ou civil;

- geração de emprego;

- criação e utilização de redes e recursos territoriais;

- consolidação da identidade e da cooperação locais.

O estudo de caso foi entendido e interpretado enquanto processo de valorização dos recursos locais e oportunidade para o desenvolvimento regional. Para tanto, o referencial teórico principal é constituído pela teoria de Sérgio Boisier sobre "capital territorial sinérgico" e cultura do desenvolvimento (BOISIER, 1999).

O autor identifica seis fatores que estariam diretamente vinculados ao surgimento de territórios organizados e de processos de desenvolvimento regional. Estes são: recursos, atores, instituições, procedimentos, cultura e inserção no entorno. As diferentes formas de capital que é possível encontrar em um território (organizado), se adequadamente articuladas entre si, produzem desenvolvimento. Tal articulação derivaria da atribuição de valor ativo à forma mais importante de capital que seria possível encontrar em qualquer comunidade: o capital sinergético (BOISIER, 1999).

Boisier define o capital sinérgico como a capacidade social de promover ações conjuntas, destinadas a fins coletiva e democraticamente aceites, com o resultado de se obter um produto final maior do que a soma dos componentes (BOISIER, 1999).

Pelo que concerne à definição e compreensão do conceito de "capital social", a obra de Coleman (1990) e Putnam (1993) representa o referencial fundamental. Esta foi integrada pela reflexão de alguns estudiosos dos percursos compartilhados de desenvolvimento territorial e patrimonialização dos recursos locais (CALLON, 1986; AKRICH et al., 2006; BRUNORI et al., 2006a, 2006b e 2006c; BELLETTI et al., 2006). Segundo esses autores, o capital social (ou relacional), isto é, o potencial de ação coletiva ligado às redes familiares, fraternais, associativas, cívicas, profissionais, etc. compõe o "capital territorial" (com o capital natural, o capital cultural e o capital humano). A mobilização desses conjuntos de recursos propicia a criação de capital simbólico, o qual, ao fundar relações de confiança, reciprocidade e pertencimento ao sistema, sustenta todos os circuitos necessários à criação de valores materiais e imateriais (monetizáveis e não monetizáveis), entre os quais o capital econômico (AKRICH et al., 2006).

No entendimento de Akrich e do grupo de estudiosos liderado por Brunori e Belletti, o conceito de "ciclo de tradução" é o que permite descrever as dinâmicas e os elementos que intervêm nos processos sociais de aprendizagem, capacitação, inovação e valorização dos estoques de recursos (capitais) locais. O termo "tradução" deve-se às necessárias fases transformativas que os ciclos de ativação de relações requerem: uma série de operações de reformulação e representação de objetos e temas insignificantes e sem valor, a priori, mas que começam a adquirir valores à medida que circulam pelas redes e pelos atores. Segundo Akrich et al. (2006), as quatro fases que compõem um ciclo de tradução são: (1) problematização; (2) envolvimento; (3) participação (ou atribuição dos papéis); e (4) mobilização dos atores locais. Portanto, segundo os autores, os recursos mobilizados no começo de qualquer 
projeto de valorização são constituídos pelos capitais natural, humano, cultural e social e derivam de uma interação complexa, no tempo, entre território e comunidade local, da mesma forma que sua preservação depende da consciência compartilhada de dispor de recursos potenciais e da vontade de conservar e patrimonializá-los (BRUNORI et al., 2006a, 2006b e 2006c; BELLETTI et al., 2006). A valorização, em substância, é uma negociação e uma construção social. Foi adotado o enfoque analítico do ciclo de tradução para formular indicadores e roteiros para a pesquisa de campo e interpretar os resultados da experiência observada.

\section{A COOPERCUC: HISTÓRIA, ESTRUTURA E FUNCIONAMENTO}

No sertão compreendido entre as cidades de Juazeiro, Paulo Afonso e Euclides da Cunha (BA), no centro do chamado "polígono das secas", algumas famílias de agricultores dos municípios de Uauá, Canudos e Curaçá (Figura 1) deram vida à experiência da Coopercuc para o beneficiamento e comercialização dos frutos nativos da região, especialmente umbu e maracujá da Caatinga.

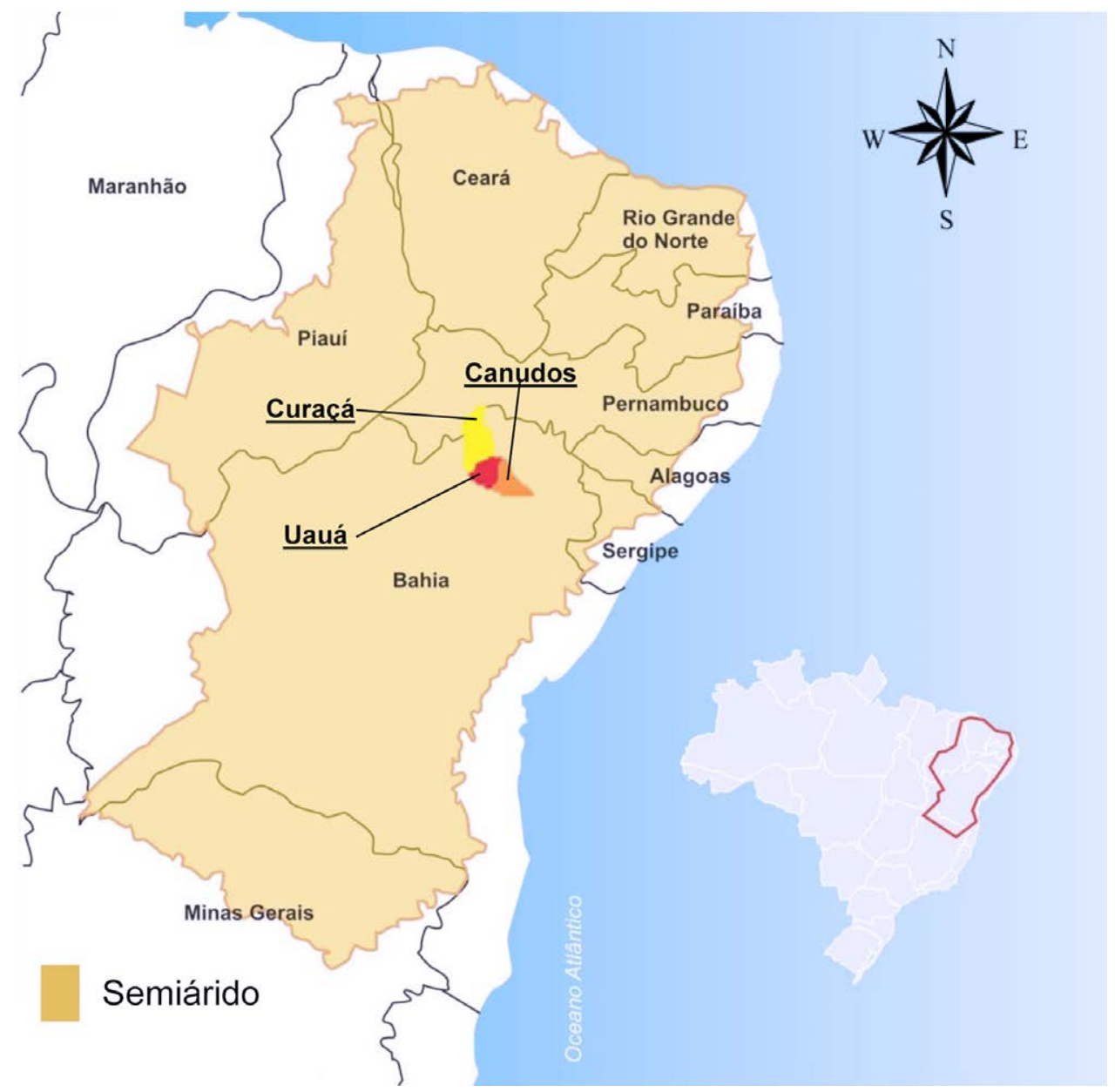

Figura 1 - Área de abrangência do semiárido brasileiro e da região de estudo.

Fonte: Adaptado de Agência Nacional de Águas (ANA) / Ministério da Integração Nacional (MI).

Na década de 1980, em algumas comunidades rurais de fundo de pasto do município de Uauá e circunvizinhas enraizaram ações de catequização e conscientização realizadas por religiosos ativos nas pastorais sociais e foram surgindo Comunidades Eclesiais de Base (CEBs). O trabalho da Igreja foi o primeiro agente para a mudança. Grupos de mulheres eram reunidos por freiras missionárias que ensinavam a aproveitar frutos e plantas espontâneas para fins alimentares e medicinais. Paralelamente, homens e mulheres das comunidades participavam de momentos de oração e discussão: a ação da Pastoral da Terra e a atuação das Comunidades Eclesiais de Base trabalhavam para a conscientização política e a organização social. 
Em 1989, começou na região o trabalho de convivência com o semiárido que, a partir de 1992, foi intensivamente intermediado pelo Instituto Regional da Pequena Agropecuária Apropriada (IRPAA). 0 Programa de Convivência com o Semiárido em Canudos, Uauá e Curaçá (Procuc) do IRPAA, realizou, durante uma década, intervenções sociais de capacitação voltadas para os agricultores familiares e as mulheres da região. Dessa forma, os grupos de mulheres das comunidades que, graças ao trabalho das freiras, já tinham iniciado a "redescoberta" das potencialidades dos frutos do sertão, participaram em ações de diferente natureza, desde a discussão sobre recursos alternativos para geração de renda até a assistência técnica para o aproveitamento das frutas nativas destinadas ao consumo familiar. As reuniões e encontros frequentes proporcionaram oportunidades de debate e formação, com o objetivo geral de melhorar a condição de vida e a segurança alimentar da população rural.

Ao longo dos anos, as comunidades continuaram recebendo cooperantes voluntários e agentes de programas de capacitação e desenvolvimento, nacionais e internacionais. Com eles, chegaram auxílios financeiros e uma ideia nova, em linha com o trabalho que já vinha sendo desenvolvido nas comunidades: trabalhar no beneficiamento dos recursos locais, primeiramente o umbu, para a sua valorização comercial.

A partir de 1998, as mulheres dos povoados começaram a processar artesanalmente a fruta nos espaços domésticos, transformando as frutas em doces, compotas e geleias. Ainda, começaram a levar esses produtos para a cidade e a vendê-los nas feiras locais.

A atividade das famílias de produção e venda cresceu constantemente e, em 2003, um projeto da Catholic Relief Service (CRS, organização Caritas dos Estados Unidos) financiou a construção de uma unidade de beneficiamento de frutas, situada na cidade de Uauá, e que apoia o trabalho de produção caseira realizado nas comunidades rurais. A fábrica iniciou sua atividade em 2004. Nesse mesmo ano, aconteceram dois eventos centrais para o decorrer da experiência: a oficialização legal da cooperativa Coopercuc e a participação de produtores da cooperativa na Feira Nacional de Agricultura Familiar, em Brasília. Em Brasília, os consultores do Ministério do Desenvolvimento Agrário (MDA), que na época estavam assessorando a implementação de alguns projetos do movimento Slow Food no Brasil ${ }^{1}$, tiveram a oportunidade de conhecer o umbu e suas potencialidades gastronômicas e resolveram iniciar um projeto de valorização ulterior para o produto e as comunidades da região.

Os produtores ganharam, como incentivo inicial do Slow Food, um financiamento de 13.000 euros que foi investido para a construção de 13 pequenas unidades de beneficiamento, situadas em 13 comunidades rurais dos três municípios. Em 2004, graças à visibilidade garantida pelo Slow Food, os produtos da Coopercuc começaram a ser exportados e vendidos na França. A partir de então, os produtores da Coopercuc se demonstraram capazes de encontrar, sozinhos, acompanhamento e apoio financeiro necessários para melhorar a produção e a comercialização.

O volume de produção e vendas da cooperativa foi crescendo tanto ao longo dos anos que seus membros começaram a procurar diversas instituições que ministrassem cursos de capacitação técnica e administrativa, com o objetivo de tornar os integrantes da cooperativa funcionários e gestores cada vez mais capazes e autônomos.

Atualmente, a Coopercuc trabalha com a fábrica central, na cidade de Uauá, e com 18 unidades de beneficiamento localizadas em 18 comunidades rurais. $O$ número de pessoas envolvidas aumentou constantemente ao longo dos últimos anos, passando de 44 sócios, em 2004, para os 180 atuais. Destes, 65\% são mulheres. Hoje, as famílias trabalhando na cooperativa são cerca de 450.

No que diz respeito à distribuição dos produtos, a legalização da cooperativa, a capacidade de captar e investir recursos, a certificação orgânica e sua ampla rede de contatos têm garantido à Coopercuc vários canais e acordos de comercialização, no mercado interno e externo. Entre eles, destacam-se: a Companhia Nacional de Abastecimento, o Programa de Aquisição de Alimentos, o Programa Nacional de Alimentação Escolar, lojas varejistas em vários estados brasileiros, supermercados Walmart de Salvador e a rede nacional Pão de Açúcar, além de exportações para a França. 
Graças à capacitação e à especialização técnica de seus membros, a Coopercuc dispõe de uma organização interna por setores específicos, nos quais trabalham 15 funcionários especializados. Desde a sua fundação, os cargos da diretoria são equitativamente distribuídos e revezados entre representantes dos grupos de cada um dos três municípios, visando manter um modelo participativo, rotativo e descentralizado. O lucro anual da cooperativa é repartido entre os grupos comunitários de sócios-produtores, segundo a quantidade produzida naquele ano por cada grupo.

A Coopercuc realiza constantemente atividades de formação profissional e educação por meio de cursos de cunho ambiental destinados aos jovens e adultos das comunidades rurais. A atenção para com aspectos de sustentabilidade ambiental, além disso, é expressa nas regras estabelecidas pelos protocolos de produção adotados pela cooperativa.

Ao longo do tempo, a história da valorização do umbu e das famílias de agricultores familiares de Uauá, Canudos e Curaçá tem sido nacional e internacionalmente reconhecida. No Brasil, a cooperativa é pioneira em um modelo de negócios e produção sustentável dentro dos princípios da economia solidária e do comércio justo. No Nordeste, hoje, a Coopercuc é referência na gestão cooperativista, beneficiamento e comercialização de produtos da agricultura familiar.

\section{RESULTADOS E DISCUSSÃO}

Levando em conta o princípio da convivência com o semiárido e algumas reflexões da ciência social sobre capital social, processos de criação e valorização dos recursos locais e da cultura do desenvolvimento, consideramos a experiência e o legado da Cooperativa Agropecuária Familiar de Canudos, Uauá e Curaçá (Coopercuc), aqui apresentados por meio da reconstrução de sua história e resultados, como sendo um exemplo de sucesso e um conjunto de boas práticas.

O crescimento que a experiência da Coopercuc tem proporcionado para os integrantes da cooperativa e habitantes da região se desdobra em vários sentidos. Graças ao trabalho e ao sucesso da Coopercuc, a região deixou de ser conhecida apenas pelas secas e a pobreza, como a "terra da vaca morta", conforme alguns depoimentos. Devido ao trabalho com o umbu, a população local logrou valorizar e patrimonializar, de forma ambientalmente atenta e regrada, os recursos oferecidos pela natureza local, isto é, reconheceu sua disponibilidade, aprendeu a transformá-los em fontes de benefícios materiais e imateriais, compartilhados e reprodutíveis para a comunidade e em prol das gerações sucessivas (BRUNORI et al., 2006a, 2006b e 2006c; BELLETTI et al., 2006), aprendendo, ao mesmo tempo, a gerir os limites objetivos e as características do semiárido.

A implantação exitosa de um arranjo produtivo autônomo, autogerido e participativo, ao longo das décadas, mostra ter reforçado a confiança e o empoderamento dos atores sociais, que passaram a se perceber como capazes de assumir a gestão do seu próprio destino, individual e coletivo, do ponto de vista econômico, político e social. Hoje em dia, eles são autores conscientes e responsáveis, cientes da própria origem, do acompanhamento e das ferramentas que foi necessário adquirir durante o processo. A partir de um determinado momento da história, eles mesmos, deixando de receber, começaram a demandar, a buscar e a providenciar para si essas ferramentas. Esse processo, durante mais de 30 anos, foi acompanhado por um continuado e, até hoje, crescente envolvimento direto com a vida política da cidade e da região. $O$ engajamento político ativo nas administrações locais, resultando na organização e articulação do tecido social é, sem dúvida, um ingrediente importante dessa narração.

No que diz respeito aos ganhos econômicos vindos do trabalho com as frutas nativas, estes têm sido traduzidos em melhorias significativas, tanto materiais como "imateriais" (não monetários), das condições de vida.

Atualmente, na região Nordeste, a coleta e a venda de sacos de fruta fresca para intermediários ou, diretamente, nas feiras e ao lado das estradas, representam a forma mais difusa de exploração do recurso. Durante poucos meses no ano, essa atividade extrativista é responsável por uma parte importante da renda de muitas famílias. Realizada da forma comum, a exploração do recurso natural agrega o mínimo de valor, o qual fica integralmente nas mãos dos intermediários comerciais. A 
organização dos agricultores da Coopercuc significou uma melhor e maior valorização dos produtos no mercado - sem dispersão de lucro - e o envolvimento de um número crescente de famílias no processo.

A cota de lucros que a cooperativa repassa a seus membros, em particular às mulheres que trabalham nas unidades de beneficiamento, representa um complemento de renda significativo (um acréscimo de $30 \%$, segundo dados da cooperativa), que se traduz tanto em termos monetários, como de crescimento social coletivo. Os atores locais falam de uma "mudança real" na qualidade e na vida das pessoas. As melhorias repercutem de maneira evidente nas habitações, que todos, ao longo do tempo, conseguiram reformar e equipar com banheiro, telhado, piso e eletrodomésticos básicos. Logo em seguida, a renda complementar é investida para os estudos dos filhos e a compra de instrumentos para o trabalho agrícola. É por isso que, como resume uma das pessoas entrevistadas: "Quem andava a pé, começou a andar de bicicleta; quem andava de bicicleta, passou a andar de moto. E aí vai melhorando, a cada ano assim".

Atualmente, graças ao nível de estruturação e aos números da produção alcançados pela cooperativa, existe uma fonte de emprego local viável e atrativa. Além disso, a escolaridade média dos cooperados, declaram os entrevistados, é bem acima da média do Nordeste brasileiro. Os filhos e netos dos fundadores da Coopercuc estão frequentando cursos universitários.

Em relação à participação no processo produtivo e à distribuição de funções, desde o começo do processo, os homens aprenderam e incorporaram uma visão nova do valor do papel da mulher na comunidade e do trabalho feminino. Desde sempre, o trabalho de valorização das frutas nativas e, mais tarde, a organização interna da cooperativa, propiciaram uma mudança cultural profunda a tal respeito. Do umbu, insistem os entrevistados, surgiu uma experiência de grande força pedagógica, fundada sobre a aprendizagem do valor da oportunidade e da responsabilidade.

Podemos afirmar que a avaliação global do estudo de caso apresenta respostas positivas para todos os indicadores qualitativos adotados para a pesquisa exploratória de campo, mostrando níveis especialmente altos no que diz respeito à continuidade e à autonomização da experiência. Os atores souberam reconhecer, mobilizar e incrementar repositórios de capitais, tangíveis e intangíveis (entre eles, capital natural, econômico, cognitivo, simbólico, cultural, institucional, psicossocial, social e cívico), estimulando uma difusa confiança interpessoal e organizacional (BOISIER, 1999).

Analisado do ponto de vista do envolvimento crescente dos atores locais e dos níveis de identificação com os projetos, assim como do ponto de vista dos processos sociais de aprendizagem, capacitação, inovação e valorização dos estoques de recursos, o histórico da Coopercuc apresenta resultados positivos. O estudo dos que poderiam ser considerados ciclos de tradução (CALLON, 1986; AKRICH et al., 2006; BRUNORI et al., 2006a, 2006b e 2006c; BELLETTI et al., 2006) mostra que as fases de problematização, envolvimento, participação e mobilização dos recursos e dos atores locais ocorrem na base, de forma tendencialmente compartilhada e difusa.

A experiência da Coopercuc e a análise da sua história apontam para resultados que se traduzem em um corolário de benefícios em diversos âmbitos e que vão de encontro aos fatores desagregadores do semiárido e na definição de suas problemáticas socioeconômicas:

a) a valorização ambientalmente atenta e regrada dos recursos oferecidos pela natureza local, feita por meio da gestão consciente dos limites objetivos e características do meio local e proporcionada por formas de educação contextualizada, permite "redimir" a ideia negativa da natureza hostil e hostilizada;

b) o empoderamento para a gestão autônoma do projeto coletivo consolida a atitude proativa em lugar da postura passiva de espera e do assistencialismo;

c) as comunidades alcançam organização e mobilização em volta de um projeto coletivo, fonte de renda e de empregos; 
d) a disponibilidade de uma fonte de renda e emprego in loco ajuda a conter o êxodo rural e a orientar os percursos formativos das novas gerações (estudos de agronomia, tecnologia alimentar, entre outros);

e) foi indicada e encontrada uma solução concreta para as questões de desnutrição e segurança alimentar da população;

f) a experiência tem oferecido um canal eficaz para a mudança cultural, efetiva e concreta, em prol da integração virtuosa das mulheres na economia local, como mão de obra qualificada e reconhecida, regularmente empregada e remunerada de forma justa.

Pelo que concerne o conjunto de resultados e benefícios alcançados pela Coopercuc, cabe o questionamento acerca dos possíveis motivos que os determinaram. Nossa hipótese, aqui esboçada de forma apenas incipiente e que poderia ser melhor explorada por futuras pesquisas, apontaria para um fator originário, representado pelo trabalho de conscientização realizado pelo que poderíamos chamar de "primeiros agentes de desenvolvimento" (as freiras e padres das pastorais sociais e que acompanharam as (EBs). A aprendizagem prática vinda desse trabalho inicial serviu como marco e memória coletiva de um percurso e da possibilidade de resgate. Isso fixou e mobilizou importantes repositórios de capital social disponível (COLEMAN, 1990; PUTNAM, 1993) e, ao mesmo tempo, a lembrança dos percursos para acessá-lo. Ao ser acompanhado por um trabalho de capacitação, conscientização, educação, responsabilização e empoderamento constante e profundo - feito a partir da dimensão existencial e religiosa do comprometimento ético-moral do indivíduo para com a coletividade - tal processo se consolidou, e se tornou disponível para todos os processos, projetos e iniciativas de crescimento e desenvolvimento local que se sucederam.

Ao longo do trabalho foram feitas várias suposições, explícitas e implícitas. Identificamos, finalmente, algumas limitações do estudo que, uma vez corrigidas, poderiam contribuir para dar suporte a tais inferências. Primeiramente, chamamos a atenção para a necessidade de ampliar a pesquisa de campo ao resto de municípios que integram a Coopercuc. Embora a cooperativa tenha surgido em Uauá, incorporar os municípios de Curaçá e Canudos, apesar de representar um substancial aumento do esforço de pesquisa, teria ajudado a ampliar os objetivos desta última. Em segundo lugar, a abordagem indutiva apresentada poderia ter sido complementada por uma metodologia mais experimental, por meio de: (i) aplicação de um estudo por amostragem em algumas comunidades da área de estudo; (ii) uso de indicadores quantitativos, visando a obtenção de parâmetros de referência para medir os benefícios da experiência analisada.

\section{CONSIDERAÇÕES FINAIS}

A compreensão do semiárido e das criticidades de seu meio socioeconômico precisa ser ampla, de modo a considerar as diversas dimensões e peculiaridades que os definem, desde os fatores naturais até os elementos históricos e políticos. É preciso evitar deduções lógicas simples e deterministas em relação ao fator "seca", já que muitas das causas do atraso econômico regional do semiárido devem ser buscadas nos padrões de ocupação e nos arranjos sociais e produtivos historicamente consolidados na região.

Condizentemente com os princípios da ideia-projeto de convivência com o semiárido, os membros da Coopercuc, em vez de sentirem-se "vítimas da seca", se tornaram sujeitos ativos e propositivos de direito e cidadania, transformando as oportunidades de capacitação que foram sendo oferecidas - a partir de recursos locais - em caminhos de organização social autônoma e em benefícios coletivos.

Embora reconheça as dificuldades impostas pelas condições climáticas adversas do semiárido e as fragilidades associadas, o estudo mostra a possibilidade e as potencialidades de alternativas localmente integradas e sustentáveis.

Em sentido oposto à maioria das políticas e ações para o semiárido vindas do Estado, que desconsideram a necessidade de conviver com as condições ambientais desse espaço geográfico e adotar sistemas 
produtivos apropriados e calibrados na realidade social local, a experiência da Coopercuc apresenta percursos possíveis para o desenvolvimento regional.

\section{NOTA}

${ }^{1} \mathrm{O}$ movimento Slow Food nasceu na Itália em 1989. Hoje é constituído como associação internacional com mais de 100.000 membros em 150 países do mundo e atua para a proteção e promoção de alimentos e variedades tradicionais de qualidade, tendo por base a conservação de métodos de cultivo e processamento ecologicamente atentos, a defesa da biodiversidade e a tutela das comunidades de produtores e do conjunto de valores históricos, artísticos, culturais e identitários contidos nas heranças alimentares (ANDREWS, 2008; SLOW FOOD, 2013).

\section{REFERÊNCIAS}

ANA. AGÊNCIA NACIONAL DE ÁGUAS. Disponível em: <http://www2.ana.gov.br/Paginas/default.aspx> Acesso em: 14 out. 2016.

AKRICH, M.; CALLON, M.; LATOUR, B. Sociologie de la traduction. Textes fondateurs, Paris: Editions Mines de Paris, 2006.

ALVES, A. Convivência com o Semiárido Brasileiro. In: CONTI, I. L.; OSCAR, E. Convivência com o Semiárido Brasileiro: autonomia e protagonismo social. Editora IABS: Brasília, DF, p. 35-44, 2013.

ALVES, E.; SOUZA, G. S. O Semiárido segundo o Censo Agropecuário 2006 e os censos de população 1991, 2000 e 2010. Revista de Política Agrícola, n. 1, p. 74-85, 2015.

ANDREWS, G. The Slow Food Story. Politics and Pleasure. London: Pluto Press, 2008.

ARAÚJO, L. A.; LIMA, J. P. R. Transferências de renda e empregos públicos na Economia sem produção do semiárido nordestino. Planejamento e políticas públicas, n. 33, p. 45-77, 2009.

BAPTISTA, N. Q.; CAMPOS, C. H. Possibilidades de construção de um modelo sustentável de desenvolvimento no Semiárido. In: CONTI, I. L.; SCHROEDER, E. O. (Org.). Convivência com o semiárido brasileiro: autonomia e protagonismo social. Brasília: Editora IABS, p. 73-88, 2013 .

Educação contextualizada para a convivência com o Semiárido. In: CONTI, I. L.; SCHROEDER, E. O. (Org.). Convivência com o semiárido brasileiro: autonomia e protagonismo social. Brasília: Editora IABS, p. 99-114, 2013b.

Formação, organização e mobilização social no Semiárido brasileiro. In: CONTI, I. L.; SCHROEDER, E. O. (Org.). Convivência com o semiárido brasileiro: autonomia e protagonismo social. Brasília: Editora IABS, p. 89-98, 2013c.

Caracterização do semiárido brasileiro. In: CONTI, I. L.; SCHROEDER, E. O. (Org.). Convivência com o semiárido brasileiro: autonomia e protagonismo social. Brasília: Editora IABS, p. 55-62, 2013d.

BAPTISTA, N. Q.; CAMPOS, C. H. Fatores históricos, sociais, culturais e políticos do Semiárido. In: Estratégias de convivência com o semiárido brasileiro: textos e artigos para alunos(as) participantes. Brasília: Editora IABS, p. 27-34, 2014.

BELLETTI, G. et al. Il processo di valorizzazione delle produzioni agroalimentari tipiche. In: ROCCHI, B.; ROMANO, D. (a cura di). Tipicamente buono. Concezioni di qualità lungo la filiera dei prodotti agroalimentari in Toscana. Milano: Franco Angeli, 2006.

BOISIER, S. El desarrollo territorial a partir de la construcción de capital sinergético. In: Revista Brasileira de Estudos urbanos e regionais, n. 2 /, p. 39-53, novembro 1999.

BRASIL. Lei Orgânica de Segurança Alimentar e Nutricional - Lei 11.346 de 15 de setembro de 2006.

BRASIL. MINISTÉRIO DA INTEGRAÇÃO NACIONAL. Nova Delimitação do Semiárido Brasileiro. IICA, 35 p., 2005. 
Plano Estratégico de Desenvolvimento Sustentável do Semiárido. IICA, p. 137, 2005. Disponível em:<http:// www.mi.gov.br/c/document_library/get_file?uuid=dfcd33d2-f5b6-4de3-bf28-d303ca22510a\&groupld=24915> Acesso em: 15 out. 2016.

BRUNORI, G. et al. Marketing Sustainable Agriculture: an analysis of the potential role of new food supply chains in sustainable rural development Policy Recommendations and Practical Protocols - Italian National Report. SUSCHAIN deliverables, n. 20 \& 21, 2006a.

BRUNORI, G. et al. Raw sheep milk cheese of Pistoia mountains - Case study report. SUS-CHAIN deliverable, $\mathrm{n}$. 16.4a, p. 1-39, 2006b.

BRUNORI, G. et al. L'analisi dell'organizzazione dei sistemi socio-economici dei prodotti tipici attraverso l'approccio di network. In: ROCCHI, B.; ROMANO, D. (a cura di). Tipicamente buono. Concezioni di qualità lungo la filiera dei prodotti agroalimentari in Toscana. Milano: Franco Angeli, p. 97-116, 2006c.

BUAINAIN, M.; GARCIA, J. R. Desenvolvimento rural do semiárido brasileiro: transformações recentes, desafios e perspectivas. Confins, n. 19, 2013. Disponível em: <https://confins.revues.org/8633?lang=pt>Acesso em: 15 out. 2016.

BURITY, V. et al. Direito Humano à Alimentação Adequada no Contexto da Segurança Alimentar e Nutricional. ABRANDH, Brasília, 2010.

BURSZTYN, M. O poder dos donos: planejamento e clientelismo no Nordeste. Petrópolis: Vozes, 1984.

BURSZTYN, M.; CHACON, S. S. Ligações perigosas: proteção social e clientelismo no Semiárido nordestino. Estud. Soc. e Agric., v. 19, p. 30-61, 2011.

CALLON, M. Some Elements of a Sociology of Translation: Domestication of the Scallops and the Fishermen of St. Brieuc Bay. In: LAW, J. Power, action and belief: a new sociology of knowledge? London: Routledge, p. 196-223, 1986.

CASTRO, J. Geografia da fome. 3. ed. Rio de Janeiro: Civilização Brasileira, 2003.

COLEMAN J. S. Foundations of social Theory. Cambridge, MA: Harvard University Press, 1990.

CONTI, I. L.; PONTEL, E. Transição paradigmática na convivência com o semiárido. In: CONTI, I. L.; SCHROEDER, E. O. (Org.). Convivência com o semiárido brasileiro: autonomia e protagonismo social. Brasília: Editora IABS, p. 29-38, 2013.

CORDEIRO, D. L. Reinvenção dos movimentos sociais no Semiárido brasileiro: o caso do P1MC. In: CONTI, I. L.; SCHROEDER, E. O. (Org.). Convivência com o semiárido brasileiro: autonomia e protagonismo social. Brasília: Editora IABS, p. 2015-2016, 2013.

FONTANA et al. Prêmio Mandacaru: projetos e práticas inovadoras de acesso à água e convivência com o semiárido. Editora IABS: Brasília, 184 p., 2015.

GEERTZ, C. The Interpretations of Cultures. Selected Essays. New York: Basic Books, 1973.

IBGE. INSTITUTO BRASILEIRO DE GEOGRAFIA E ESTATÍSTICA. Censo Agropecuário 2006. Disponível em: <http:// ibge.gov.br/home/estatistica/economia/agropecuaria/censoagro/brasil_2006/Brasil_censoagro2006.pdf> Acesso em: 17 fev. 2016.

INSA. INSTITUTO NACIONAL DO SEMIÁRIDO. Sinopse do Censo Demográfico para o Semiárido Brasileiro. Campina Grande: INSA. 2012.

INSTITUTO NACIONAL DO SEMIÁRIDO. Sistema de Gestão da Informação e do conhecimento do semiárido brasileiro. INSA. 2014. Disponível em: <http://www.insa.gov.br/sigsab/> Acesso em: 17 fev. 2016.

LEAL et al. Ecologia e conservação da caatinga. Ed. Universitária da UFPE: Recife. 2003. 822 p. Disponível em:<http://www.mma.gov.br/estruturas/203/_arquivos/5_livro_ecologia_e_conservao_da_caatinga_203.pdf> Acesso em: 17 fev. 2016. 
MALVEZZI, R. Semiárido: uma visão holística. Brasília: Confea, 2007.

MARENGO, J. A. Vulnerabilidade, impactos e adaptação à mudança do clima no semiárido do Brasil. In: CGEE. Parcerias Estratégicas. Mudança do Clima no Brasil: vulnerabilidade, impactos e adaptação, 361 p., 2008.

MIRANDA, C.; TIBÚRCIO, B. (Org.) A nova cara da pobreza rural: desenvolvimento e a questão regional. (Série desenvolvimento rural sustentável, v. 17). Brasília, IICA. 2013.

NEVES, F. C. Getúlio e a seca: políticas emergenciais na era Vargas, Revista Brasileira de História, v. 21, n. 40, p. 107-131, 2001.

A ideologia de uma natureza perversa: seca, trabalho, conflito social. In: FILHO, F. A. S.; MOURA, A. D. Memórias do Fórum Natureza e Sociedade nos Semiáridos. Fortaleza: BNB/Funceme, p. 135-145, 2006.

PEREIRA, E. S. Educação Contextualizada e Convivência com o Semiárido: lutas, conquistas e desafios. In: CONTI, I. L.; SCHROEDER, E. O. Convivência com o Semiárido Brasileiro: autonomia e protagonismo social. Editora IABS, Brasília, 208 p., p. 115-124, 2013.

PUTNAM, R. D. Making Democracy Work: Civic Traditions in Modern Italy. Princeton, NJ: Princeton University Press, 1993.

ROCHA, J. C. Soberania e segurança alimentar no Semiárido. In: CONTI, I. L.; SCHROEDER, E. O. (Org.). Convivência com o semiárido brasileiro: autonomia e protagonismo social. Brasília: Editora IABS, p. 125-134. 2013.

SANTOS, J. M. O papel da mulher na produção. In: CONTI, I. L.; SCHROEDER, E. O.; MEDAGLIA, V. R. (Org.). Construindo saberes, cisternas e cidadania: formação para a convivência com o semiárido brasileiro. Brasília: Editora IABS, p. 124-125, 2014.

SANTOS et al. Construindo saberes para uma educação contextualizada. Feira de Santana: MOC, 124 p., 2011. Disponível em: <http://plataforma.redesan.ufrgs.br/biblioteca/pdf_bib.php?COD_ARQUIVO=10485> Acesso em: 15 out. 2016.

SCHISTEK, H. O Semiárido brasileiro: uma região mal compreendida. In: CONTI, I. L.; SCHROEDER, E. O. (Org.). Convivência com o semiárido brasileiro: autonomia e protagonismo social. Brasília: Editora IABS, p. 41-54, 2013a.

SEDDON et al. Sensitivity of global terrestrial ecosystems to climate variability. Nature, v. 531, p. 229-232, 2016.

SILVA, R. M. A. Entre o combate à seca e a convivência com o semiárido. Tese (Doutorado em Desenvolvimento Sustentável). Centro de Desenvolvimento Sustentável, Universidade de Brasília, 2006.

SILVA, M. L. M.; RODRIGUES, A. O.; SILVA, S. L. Transformações e protagonismo social no Semiárido. In: Estratégias de convivência com o semiárido brasileiro: textos e artigos para alunos(as) participantes. p. 38-58. Editora IABS: Brasília, 2014.

SLOW FOOD. Bem-vindos ao nosso mundo. O manual. Bra (Cn): Slow Food, 2013.

VALENTE, F. L. S. Do Combate à Fome à Segurança Alimentar e Nutricional: o Direito à Alimentação Adequada. Revista de Nutrição da PUCCAMP, Campinas. 10 (1): 20-36, jan./jun. 1997. 